\title{
Renovascular hypertension in three children from one family
}

\author{
P. M. BLOM VAN ASSENDELFT, ${ }^{1}$ C. J. KOOIKER, E. J. DORHOUT MEES,
} AND A. J. HAMELEERS

From the Renal Division, Department of Medicine, University Hospital, Utrecht, the Pathological Institute, University of Utrecht, and the Department of Cardiology, St Elisabeth Hospital, Almelo,

The Netherlands

SYNOPSIS Hypertension as a result of stenosis of a renal artery was diagnosed in three patients, aged 20,17, and 9 respectively, among 14 siblings from one family. The oldest patient was treated by vasoplasty; a hypoplastic kidney had previously been removed in an unsuccessful attempt to control hypertension. Nephrectomy was performed in the other two patients. The pathological picture of the main renal artery that could be examined differed from that usually seen in the fibromuscular dysplasia group. The absence of microscopic signs of atrophy in the small kidneys behind the stenosis argues for a developmental defect. More than three years after operation blood pressure and renal function in all three patients have remained normal.

Stenosis of a renal artery is unusual in children and young adults. A familial incidence has been mentioned occasionally but without histological proof. We have observed three patients from one family, suffering from severe hypertension due to stenosis of a renal artery, who were successfully

${ }^{1}$ Present address: Sophia Ziekenhuis, Zwolle, The Netherlands Received for publication 14 March 1973. treated by surgery. The histopathological picture of these kidneys was different from the one usually seen in acquired stenosis in adults.

\section{Description of the Family}

The family consisted of two parents and 14 children (see table). After three of the children (VIII, X, and XIV) had been treated as described below, the other

\begin{tabular}{|c|c|c|c|c|c|c|}
\hline & \multirow[t]{2}{*}{ Sex } & \multirow[t]{2}{*}{ Age (yr) } & \multirow{2}{*}{$\begin{array}{l}\text { Blood Pressure } \\
\text { Upright }(\mathrm{mm} H g)\end{array}$} & \multirow{2}{*}{$\begin{array}{l}\text { Serum Creatinine } \\
(m g / l)\end{array}$} & \multicolumn{2}{|l|}{ Urine } \\
\hline & & & & & Protein & Sediment \\
\hline $\begin{array}{l}\text { Father } \\
\text { Mother } \\
\text { Children }\end{array}$ & $\begin{array}{l}\mathbf{M} \\
\mathbf{F}\end{array}$ & $\begin{array}{l}66 \\
55\end{array}$ & $\begin{array}{l}210 / 110 \\
150 / 105\end{array}$ & $\begin{array}{l}11 \cdot 0 \\
10 \cdot 9\end{array}$ & $\begin{array}{l}\text { Negative } \\
\text { Negative }\end{array}$ & $\begin{array}{l}\text { No abnormality } \\
\text { No abnormality }\end{array}$ \\
\hline I & $\mathbf{F}$ & 34 & $170 / 90$ & $8 \cdot 0$ & Negative & No abnormality \\
\hline II & $\mathbf{M}$ & 32 & $165 / 85$ & $8 \cdot 0$ & Negative & No abnormality \\
\hline III & $\mathbf{M}$ & 31 & $170 / 95$ & $11 \cdot 4$ & Negative & No abnormality \\
\hline IV & $\mathbf{M}$ & 29 & $150 / 100$ & $11 \cdot 1$ & Negative & No abnormality \\
\hline V & $\mathbf{F}$ & 28 & $150 / 90$ & $9 \cdot 3$ & Negative & $0-4$ leucocytes \\
\hline VI & $\mathbf{F}$ & 26 & $110 / 80$ & $10 \cdot 4$ & Negative & No abnormality \\
\hline VII & $\mathbf{M}$ & 24 & $210 / 90$ & $12 \cdot 0$ & Negative & No abnormality \\
\hline VIII' & $\mathbf{F}$ & 20 & $260 / 140$ & $13 \cdot 0$ & Negative & No abnormality \\
\hline IX & $\mathbf{F}$ & 21 & $145 / 105$ & $7 \cdot 6$ & Negative & No abnormality \\
\hline $\mathbf{X}^{1}$ & $\mathbf{M}$ & 17 & $220 / 120$ & $9 \cdot 0$ & Negative & No abnormality \\
\hline $\mathbf{X I}$ & $\mathbf{M}$ & 18 & $140 / 80$ & $10 \cdot 1$ & Negative & No abnormality \\
\hline XII & $\mathbf{M}$ & 17 & $165 / 105$ & $12 \cdot 0$ & Negative & No abnormality \\
\hline XIII & $\mathbf{M}$ & 15 & $120 / 80$ & $8 \cdot 2$ & Negative & Sporadic erythrocytes \\
\hline XIV' & $\mathbf{M}$ & 11 & $250 / 150$ & $8 \cdot 0$ & $2 \cdot 1 \mathrm{~g} / 1$ & No abnormality \\
\hline
\end{tabular}

Table Blood pressure, renal function, and urine analysis in the family

'The patients mentioned in the article at the date of the first examinations. 
family members were examined by one of us. They were all free of complaints, showed normal urine analysis and had serum creatinine and uric acid levels within normal limits. In most of them slight to moderate elevation of blood pressure was recorded. It cannot be excluded that similar anatomical abnormalities of lesser degree were present in some of them but it did not seem justified to perform further diagnostic investigations. The three children found to have renal artery stenosis showed an alarming clinical picture.

\section{Case Histories}

\section{PATIENT VIII}

In this girl hypertension was accidentally discovered at the age of 14. Observation elsewhere disclosed a small right kidney that was removed (see description below). After the operation blood pressure remained raised and despite vigorous antihypertensive treatment values up to $260 / 140$ were recorded.

At age 20, she was referred to our department. The ocular fundi showed spastic arteries. Creatinine clearance was $84 \mathrm{ml} / \mathrm{min}$. Serum electrolytes were normal. The electrocardiogram showed left ventricular hypertrophy. An intravenous pyelogram showed that the left kidney was slightly enlarged with a normal caliceal system. Selective angiography of this kidney disclosed a stenosis near the origin of the renal artery. A laparotomy was performed. The left renal artery appeared very tenuous, but no local stenosis was found. A longitudinal incision was made in the trunk of the artery and an ellipsoid teflon patch inserted. Postoperatively, there was a dramatic fall in blood pressure with marked orthostatic hypotension that persisted for several weeks despite a generous salt intake. Three months after the operation the orthostatic complaints had disappeared and blood pressure was $130 / 100$ recumbent and 120/80 upright. Four years later she was doing well. Blood pressure and renal function have remained normal.

\section{Morbid anatomy of the right kidney}

The microscopic section (fig 1) showed a small pelvis with a thickened but not inflamed wall. The renal tissue measured $1 \cdot 6-3 \cdot 3 \mathrm{~mm}$ in thickness. Near the pelvis there was cellular connective tissue with some wide papillary ducts: no normal renal medulla and renal papillae were present. The renal cortex contained circumscribed foci which consisted of wide thyroid-like tubules, tightly packed atrophic tubules, and solid tubular remnants without glomeruli. In the remainder of the renal cortex hypertrophic glomeruli were dispersed between wide and hypertrophic tubules. The large arteries round the

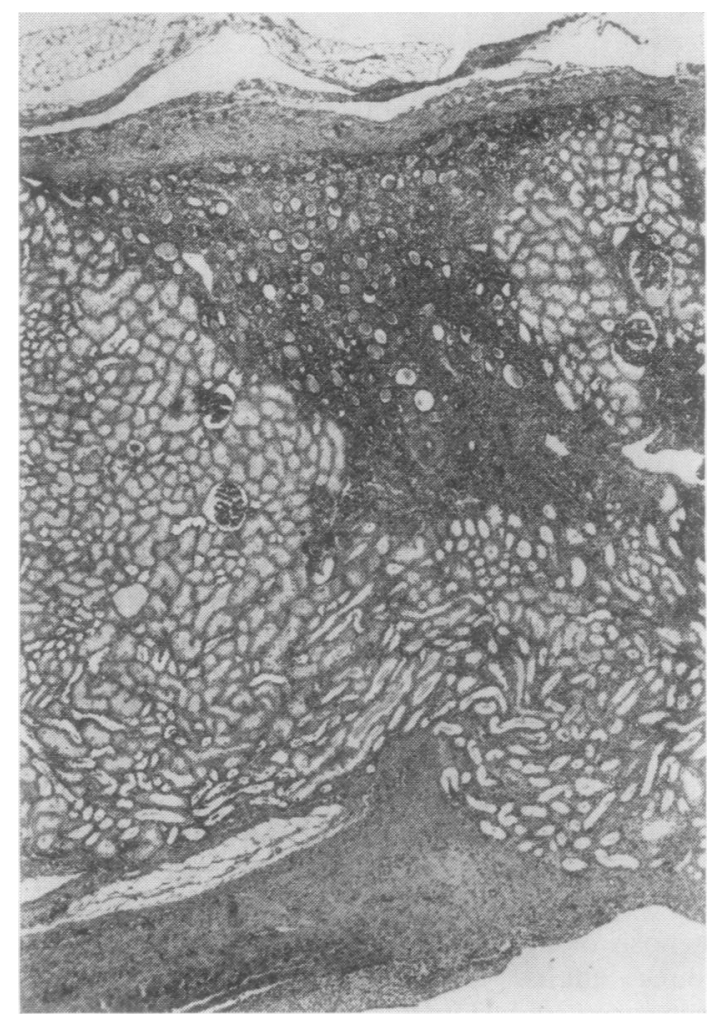

Fig 1 Patient VIII. Whole thickness of renal tissue, from renal capsule (top) to pelvic mucosa (bottom). Cortical focus of tubular atrophy; normal medullary tissue and a renal papilla are not present. Haematoxylin and eosin ( $H$ and $E): 2$ ().

pelvis, the arcuate arteries, and the interlobular arteries were thick-walled and showed muscular medial hypertrophy, hyperelastosis, and fibrocellular thickening of the intima. Some small and coiled arteries in the cortical scars seemed to be occluded by these alterations. The tissue was sporadically infiltrated by lymphocytes; no cartilage or other dysplastic structures were found. The renal artery was not available for microscopic examination.

PATIENT $x$

This boy, without complaints at that time, was found to have hypertension $(220 / 120 \mathrm{~mm} \mathrm{Hg})$ at a medical examination when aged 17. Urine examination was normal, as were serum creatinine $(9 \mathrm{mg} / \mathrm{l})$ and electrolytes. At intravenous pyelography the right kidney was smaller than the left and angiography disclosed stenosis in one of the two right renal arteries (fig 2). At laparotomy, a small right kidney with long and tenuous arteries was seen. A longitudinal 


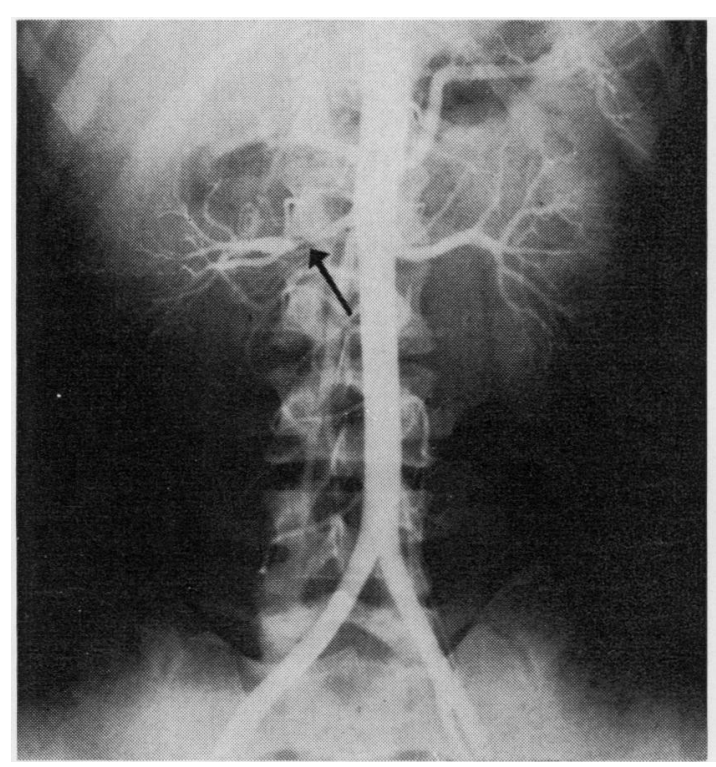

Fig 2 Patient X. Aortography shows a normal left renal artery. On the right there are two renal arteries. The upper one shows stenosis at some distance from its origin, with poststenotic dilatation. The right kidney is smaller than the left.

saphenous patch was inserted into the upper artery. The blood pressure did not drop after operation and a periarterial haematoma developed, necessitating right nephrectomy two months later. Thereafter the blood pressure returned to normal and remained so up to the last follow up $\mathbf{4 0}$ months after operation.

\section{Morbid anatomy}

The right kidney weighed $85 \mathrm{~g}$ (the renal weight of a 9-year-old child, Coppoletta and Wolbach, 1933) and had a smooth surface; its cortex was $7 \mathrm{~mm}$ thick. The renal pelvis was small, of normal shape, and lined with intact mucosa. The branches of the renal artery were of small diameter, which was not disproportionate to the size of the kidney.

Microscopically (fig 3 ) the small glomeruli showed only some occasional wrinkling of the basement membrane: the capsular spaces were empty. There was no general atrophy of renal tubules. At the vascular poles of many glomeruli there were numerous large, granulated and nongranulated epithelioid cells, which at a few glomeruli had formed spherical clusters. At some distance from the glomerulus, granulated cells were still found in the wall of some afferent arterioles. In one branch of the renal artery, near the hilus of the kidney, radially arranged smooth muscle fibres were

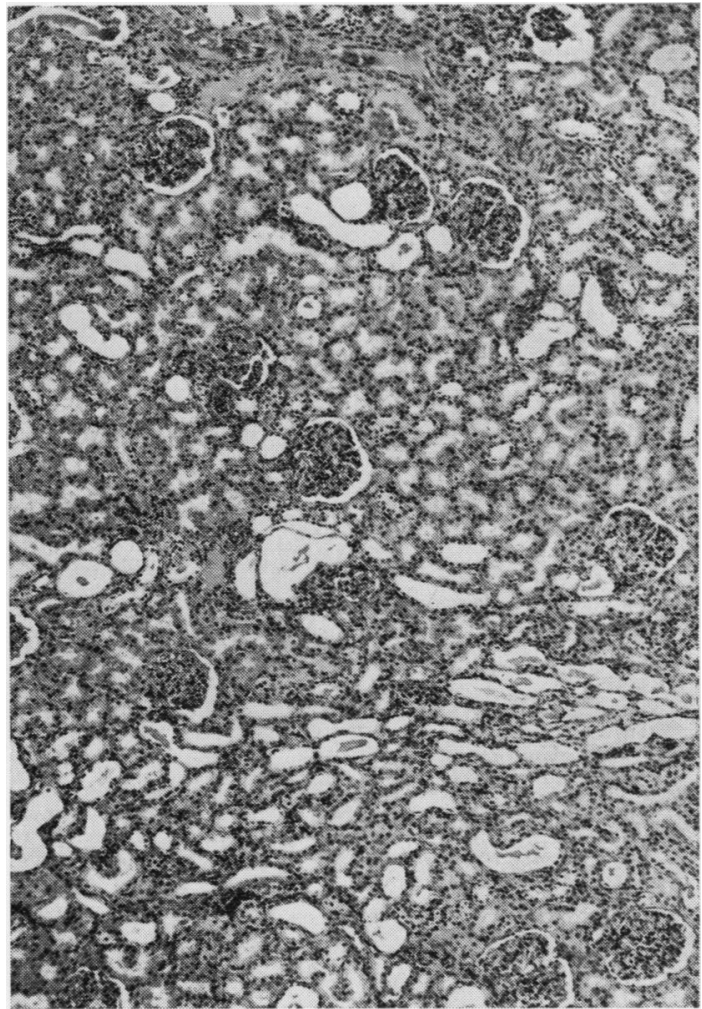

Fig 3 Patient $X$. Renal cortex showing no signs of ischaemic atrophy; dilatated tubules in medullary ray. $H$ and $E \times 50$.

present in the media, adjacent to the internal elastic lamina. The media of the intrarenal arteries was well developed without distinct abnormalities.

\section{PATIENT XIV}

The youngest son in the family was admitted to hospital when aged 11, after complaining for some months of headaches and vomiting. The blood pressure was $250 / 150 \mathrm{~mm} \mathrm{Hg}$. The ocular fundi showed very narrowed arteries. Despite vigorous antihypertensive treatment, vomiting continued, blood pressure hardly diminished, and he developed epileptic seizures after some days. The urine contained $2 \cdot 1 \mathrm{~g}$ protein per litre. Serum creatinine was normal $(8 \mathrm{mg} / \mathrm{l})$ serum sodium $134 \mathrm{~m}$-equiv/l, potassium $2.8 \mathrm{~m}$-equiv/l. Aortography disclosed an elongated stenosis starting from the origin and virtually occluding the right renal artery. At operation the right renal artery appeared hypoplastic from its origin. No pulsations were palpable and nephrectomy was performed. Postoperatively, blood pressure gradually fell to normal values. When seen 


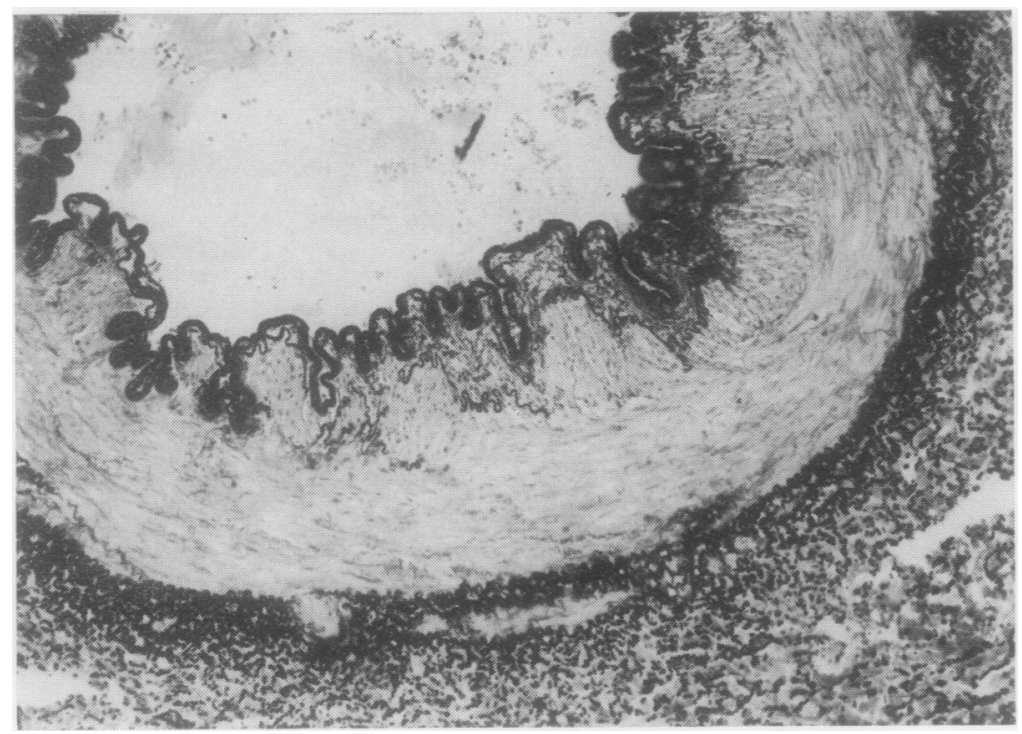

Fig 4 Patient XIV. Right renal artery with radially arranged smooth muscle fibres on the medial side of the thickened internal elastic lamina; hyperplasia of adventitial elastic tissue. Weigert-Hart elastica Van Gieson stain $\times 106$.

39 months later he was doing well with normal blood pressure and renal function (serum creatinine 10 $\mathrm{mg} / \mathrm{l})$.

\section{Morbid anatomy}

The kidney weighed $70 \mathrm{~g}$, the normal weight at this age being $94 \mathrm{~g}$ (Coppoletta and Wolbach, 1933), and had a smooth surface, the cortex being $5 \mathrm{~mm}$ thick. Microscopically the glomeruli were small with capillaries showing little unfolding; basement membranes were not wrinkled. The renal tubules showed no atrophy and the distribution of glomeruli in the parenchyma was normal. The medullary rays contained many wide tubules lined with low epithelium. At the vascular poles of many glomeruli there were numerous large, mostly granulated epithelioid cells, which at some vascular poles formed conspicuous spherical clusters. At a fair distance from the glomerulus, granulated epithelioid cells were still found in the wall of afferent arterioles. The stump of the renal artery was $4 \mathrm{~mm}$ thick, with a luminal width of about $1 \mathrm{~mm}$. The internal elastic lamina showed thickening and distinct plication; medial to this there was much elastic tissue and radially arranged smooth muscle fibres (fig 4). The adventitia of the renal artery was likewise thickened and contained smooth muscle fibres. The intrarenal arteries showed some fibrous thickening of the intima and hyperelastosis.

\section{Discussion}

The number of patients under 20 years of age with hypertension due to an abnormality of a renal artery is estimated to represent $9-26 \%$ of the total number of hypertensives in this age group (Donahoo, Leonard, Haller, and Peters, 1970) but the actual frequency may be difficult to determine because most reports deal with incidental cases. In the absence of parenchymal disease hypertension in this age group is nearly always caused by a renal vascular anomaly. To the best of our knowledge the present communication is the third in which a familial occurrence of renal vascular hypertension is reported. Thompson (in discussion, Foster, Oates, Rhamy, Klatte, Burko, and Michelakis, 1969) mentioned two sisters with 'fibromuscular dysplasia' of the renal artery; Halpern, Sanford, and Viamonte (1965) discussed three sisters with radiological evidence of fibromuscular dysplasia of the renal artery. In neither of these studies was histological confirmation of the diagnosis obtained.

In our cases $X$ and XIV kidneys and segments of renal vessels were microscopically examined. Changes in these two kidneys showed striking similarities. There was epithelioid cell hyperplasia of the juxtaglomerular system which suggests that the hypertension was related to increased renin production. The kidney of patient $X$ showed no such indications at all. In the first of our cases the previously removed kidney showed microscopically a picture of hypoplasia corresponding with that found by Ask-Upmark (1929). The renal histology of patients $\mathrm{X}$ and XIV differs markedly from that usually seen after an acquired renal arterial stenosis and, together with the renal weights, is suggestive of 
a developmental disorder of kidneys and renal arteries. The histology of these arteries points in the same direction. A conspicuous finding was the radial arrangement of smooth muscle fibres in the media, a feature not mentioned in cases of so-called fibromuscular hyperplasia or dysplasia of the media (Crocker, 1968; Harrison and McCormack, 1971). Other investigators have also reported that hypoplasia is a frequent cause of stenosis of a renal artery at an early age (Donahoo et al, 1966; Jean, Bonnet, Dumas, and Ferrand, 1969; White and Palunbinskas, 1970; Matter, Michelakis, Tinsley, and Killen, 1970).

In view of the severity of the affection and the insufficient response to medication, operative correction of the renal artery is required, particularly if found in children under the age of 10 years. Vasoplasty is considered impossible so that nephrectomy is nearly always performed. In our oldest patient, who had previously undergone nephrectomy, vasoplasty was the only recourse and proved to be successful.

Foster, Pettinger, Oates, Rhamy, Klatte, Burko, Bolasny, Gordon, Puyan, and Younger (1966) mentioned three patients who, after nephrectomy, developed stenosis of the contralateral renal artery. In two cases this was found to be due to fibromuscular dysplasia, while in the third case impaired development of the renal artery was considered. In view of the possibility of a stenosis developing in the contralateral renal artery, it is of importance to keep therapy as conservative as possible: vasoplasty is to be preferred to nephrectomy.

Although the condition rarely appears to be familial, a family study may nevertheless be profitable when hypertension is discovered in a young person, in order to detect similar disease in other siblings and prevent irreversible damage from the sometimes rapidly progressive secondary vascular changes. Early recognition may prevent a fatal outcome, as illustrated by our patient XIV.

\section{References}

Ask-Upmark, E. (1929). Über juvenile maligne Nephrosklerose und ihr Verhältnis zu Störungen in der Nierenentwicklung. Acta path. microbiol. scand., 6, 383-445.

Coppoletta, J. M., and Wolbach, S. B. (1933). Body length and organ weights of infants and children: a study of the body length and normal weights of the more important vital organs of the body between birth and twelve years of age. Amer. $J$. Path., 9, 55-70.

Crocker, D. W. (1968). Renal artery stenosis. Path. Ann., 3, 187-211.

Donahoo, J. S., Leonard, L. G. Haller, J. A., and Peters, G. N. (1970). Renovascular hypertension in children. Surg. Clin. N. Amer., 50, 801-806.

Foster, J. H., Oates, J. A., Rhamy, R. K., Klatte, E. C., Burko, H. C., and Michelakis, A. M. (1969). Hypertension and fibromuscular dysplasia of the renal arteries. Surgery, 65, 157-181.

Foster, J, H., Pettinger, W. A., Oates, J. A., Rhamy. R. K., Klatte, E. C., Burko, H. C., Bolasny, B. L., Gordon, R., Puyau, F. A., and Younger, R. K. (1966). Malignant hypertension secondary to renal artery stenosis in children. Ann. Surg., 164, 700-713.

Halpern, M. M., Sanford, H. S., and Viamonte, M., Jr. (1965). Renal artery abnormalities in three hypertensive sisters. $J$. Amer. med. Ass., 194, 512-513.

Harrison, E. G., Jr., and McCormack, L. J. (1971). Pathologic classification of renal arterial disease in renovascular hypertension. Mayo Clin. Proc., 46, 161-167.

Jean, R., Bonnet, H., Dumas, R., and Ferrand, J. L. (1969). Hypertension artérielle secondaire à une malformation vasculaire aorto-rénale chez l'enfant. Arch. franc. Pédiat., 26, 1055-1062.

Matter, B. J., Michelakis, A. M., Tinsley, E. A., and Killen, D. A. (1970). Renovascular hypertension due to bilateral renal arterial stenosis. Sth, med. J. (Bgham, Ala.), 63, 135-137.

White, A. A., and Palubinskas, A. J. (1970). Small intrarenal arterial malformation as a cause of hypertension in a child. Radiology, $95,139-140$. 